\title{
The Whole Student: Cognition, Emotion, and Information Literacy
}

\author{
Miriam L. Matteson
}

\begin{abstract}
Information literacy skill acquisition is a form of learning that is influenced by cognitive, emotional, and social processes. This research studied how two emotional constructs (emotional intelligence and dispositional affect) and two cognitive constructs (motivation and coping skills) interacted with students' information literacy scores. Two studies were carried out with a group of undergraduate students. Correlation and regression analyses revealed that emotional intelligence and motivation significantly predicted students' information literacy scores. Instruction librarians may consider incorporating greater awareness of the emotional and cognitive aspects of information literacy skill acquisition in their instructional content and delivery.
\end{abstract}

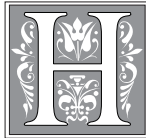

as information literacy (IL) become the sine qua non of today's college students? The students may not say so, but certainly in the field of academic librarianship it is of prime importance in practice and in research. The vibrant field of IL has addressed what content should be covered, what delivery methods work best, what skill sets should be acquired, and how to assess information literacy learning. Early notions of bibliographic instruction have given way to a larger notion of IL that encompasses the creation, dissemination, and adoption of IL standards, the integration of IL into the larger curriculum, the broadening of the content to keep pace with the explosion of digital materials, the development of multiple delivery formats and platforms, and the increased emphasis on assessing IL instruction effectiveness. But as with all things, progress propels us forward into a new era of IL.

A central component to new thinking in IL is the need to widen the lens to consider the whole student; we must see the individual characteristics across a variety of dimensions that enable a student to become information literate. Even the most thoughtfully created IL content, delivered with the most dynamic teaching methods, seamlessly integrated into a core curriculum, may not ultimately result in successful learning if students' cognitive, emotional, and social characteristics have not been considered.

Gatten models this approach by mapping theories of psychosocial and cognitive development to the steps of IL. ${ }^{1}$ He argues that librarians need to be aware of the influences of students' individual characteristics and to recognize that they move through psychosocial and cognitive developments in stages - and not necessarily in

Miriam L. Matteson is Assistant Professor in the School of Library and Information Science at Kent State University; e-mail: mmattes1@kent.edu. (C2014 Miriam L. Matteson, Attribution-NonCommercial (http:// creativecommons.org/licenses/by-nc/3.0/) CC BY-NC 
a linear fashion - as they mature. A complete understanding of how students develop and retain IL skills requires an understanding of their cognitive, emotional, and social development. For IL instruction to be the most effective, these dimensions that make up the whole student should be studied and incorporated into instructional methods. In this paper, I present data from an exploratory study that tested relationships between two of these three dimensions: students' emotional and cognitive development and their IL competency.

\section{Literature Review}

Two theoretical perspectives underpin this study. Kuhlthau's Information Search Process (ISP) demonstrates that students' information seeking exhibits consistent cognitive, behavioral, and affective dimensions. ${ }^{2}$ Although the information behavior documented in Kuhlthau's research (a term paper assignment) does not address acquisition of IL skills specifically, the fundamental premise suggests that interacting with information produces discernible and discrete feelings, thoughts, and actions that are consistent across populations and are stage specific.

In a more recent and more general treatise, Knud Illeris presents a theory of learning that argues that the process of learning includes two integrated processes, interaction and internalization, processes that occur within a field of cognitive, emotional, and social dimensions. ${ }^{3}$ In Illeris' model, each of these dimensions is activated to a varying extent while the learner is 1) interacting with the material and the environment through perception, transmission, experience, imitation, activity, or participation; and 2) internalizing and integrating the acquired knowledge with emotional patterns by accumulation (establishing new learning), by assimilation (adding new ideas to existing structures), or accommodation (reconstructing or transforming existing structures). ${ }^{4}$

Drawing from these two theories, it is reasonable to state that students experience the acquisition of IL skills similarly to other learning and that the learning process contains cognitive, emotional, and social dimensions. Furthermore, such thoughts, feelings, and social influences should interact with a student's acquisition of IL skills in ways that are detectable similarly to how thoughts, feelings, and actions were revealed in the ISP model. These theories suggest that we can uncover a more complete understanding of how students develop IL competency through examination of their cognitive, emotional, and social dimensions.

Based on this theoretical premise, four constructs were chosen to investigate how students' cognition and emotion would influence their IL competency. Emotional intelligence (EI) and dispositional affect represent the emotional dimension; motivation and coping speak to students' cognition. Although the social dimension of learning is also theoretically linked to IL, it exceeds the scope of this particular research because of constraints of the research design. However, future research should investigate how social characteristics interact with IL skill development. The four constructs are discussed below.

\section{Emotional Intelligence}

EI is the ability to recognize and understand one's emotions, recognize and understand the emotions and feelings of others, and use that awareness to inform thinking and acting. ${ }^{5} \mathrm{EI}$ is an intelligence because it involves abstract reasoning about a set of inputs - in this case emotions, as contrasted with language (verbal intelligence) or the position of objects in space (spatial intelligence). ${ }^{6}$ Although several conceptualizations of EI have been developed, including trait-based EI and a mix of trait and ability-EI, the approach that is most soundly developed in theory and research is an ability-based model of EI first put forth by Salovey and Mayer. ${ }^{7}$ The ability model posits that EI is 
an intelligence consisting of several related abilities. Emotions are viewed as sources of information, useful in helping make sense of and navigate the social environment. ${ }^{8}$ The Mayer and Salovey model of $\mathrm{EI}^{9}$ includes four branches of interrelated abilities:

1. Perceiving emotions

2. Using emotions to facilitate thought

3. Understanding emotions

4. Managing emotions

This model supposes that different individuals have varying abilities for processing information of an emotional nature and for connecting emotional processing with wider cognition. For the research presented here, I focused on the fourth branch of EI-managing emotions - as having the most relevance to IL competencies.

No research was found that tested the relationship between EI and IL, but a growing body of empirical work, across age groups, has demonstrated links between EI and general measures of academic achievement, which as an outcome measure may function similarly to a measure of IL skills. Research also shows that IL is correlated with academic achievement, further linking these two variables. For example, BowlesTerry compared the final grade point averages of students who had received library instruction at different levels of their academic career with students who had received no library instruction and found that students enrolled in upper-level library instruction had statistically significantly higher grade point averages than students who received no library instruction. ${ }^{10}$ Thus it is useful to consider academic achievement as a parallel variable to IL.

Qualter, Gardner, Pope, Hutchinson, and Whiteley found that ability-EI moderated the relationship between cognitive ability and scores on the British national General Certificate of Education in both boys and girls. ${ }^{11}$ Girls taking the national exam who had high cognitive ability and high EI outperformed their counterparts who had high cognitive ability but low EI. Boys with both high and low cognitive abilities and with high EI outperformed boys who were equally high and low in cognitive ability but low in EI. Another study of fifth and sixth graders found ability-EI significantly correlated with language arts and math grades. ${ }^{2}$ Controlling for ability in language arts, the EIto-language arts correlation was still significant, although the effect size was smaller; and controlling for math ability, the EI-to-math correlation was no longer significant. Elsewhere, EI significantly predicted GPA beyond general intelligence in college students and correlated with four of six dimensions on a nursing performance scale in a group of undergraduate and graduate nursing students. ${ }^{13}$ EI effects on academic performance are thus well established and have relevance for IL.

\section{Dispositional Affect}

Dispositional affect is a personality trait that describes how an individual typically perceives events or situations emotionally. ${ }^{14}$ Typically operationalized as positive affect (PA) and negative affect (NA), dispositional affect differs from emotions by accounting for broader, longer-lasting human reactions to experience. Where emotions arise from specific sense-making processes about events, sights, or smells, affect exists independent of a specific experience. ${ }^{15}$ PA and NA do not form opposite poles of a scale but exist simultaneously; individuals have both positive affect and negative affect at once. ${ }^{16}$ However, they are asymmetrical: we tend to recall and process negative information more than positive, feeling that "bad is stronger than good."17 Larsen explains this phenomenon this way: “...there appears to be a gain in function built into the negative affect system such that this system produces a larger response, per unit input, than the positive affect system."18 The differences between PA and NA result in disparate observable actions. For example, negative affectivity typically pairs with 
rather specific natural actions: fear goes with escape, anger goes with attack, disgust goes with expel. ${ }^{19}$ In contrast, positive affectivity is associated with approach behavior, such as staying engaged with an activity one has started. Unlike the often sudden and decisive actions associated with negative emotions, actions connected with positive emotions are vague, less urgent, and more expanding and explorative.

Thus, the "broaden and build" theory of positive emotions finds that negative affect typically results in a narrowing of the set of likely behaviors, while positive emotions result in broadening behaviors - the urge to play, be creative, savor experiences, or explore..$^{20}$ Students with a stronger negative affect who engage in information-seeking behaviors may experience greater frustration because NA's reactivity outweighs that of PA; their range of available actions may narrow. A student with greater positive disposition, on the other hand, may be able to draw on it to stay better engaged in her task and choose from a wider range of actions.

Some empirical research has examined the differential influences of PA and NA on academic achievement. In a study of 293 males from grades seven to ten, PA was found to explain more of the variance in school satisfaction, school engagement, and coping behaviors than NA. ${ }^{21}$ A study of 238 undergraduates at the University of Edinburgh revealed that academic success, as measured by course results at the end of the academic year, were predicted by a set of variables that included personality traits of agreeableness, conscientiousness, PA, task-focused coping, and emotional adaptability.22 Studies that look directly at the relationship between dispositional affect and IL do not appear to exist, but the relevant supported relationships between affect and academic achievement usefully inform this work on IL.

\section{Motivation}

Motivation, defined as the direction of a student's behavior, the level of effort expended, and the persistence of that effort, is a cognitive construct with behavioral applications. Deci and Ryan's self-determination theory distinguishes between intrinsic motivation (doing something for its inherent pleasure or interest) and extrinsic motivation (doing something for an external purpose, either to gain something desired or avoid something undesired). ${ }^{23}$ Both orientations of motivation could potentially influence students' IL competencies. Does a student have a genuine interest in learning how to understand and access information to fulfill his or her needs, to evaluate carefully and integrate that new information into individual frameworks, and to use the information effectively and ethically to accomplish a particular goal? Or does the student simply wish to earn a high grade on an assignment? Either way, motivation may be associated with IL skills.

Unlike with dispositional affect, links between motivation and IL have been discussed in the IL literature. Jacobson and Xu discuss ideas for addressing student motivation in IL courses, looking specifically at basic course design, teaching behaviors, active engagement, and student autonomy. ${ }^{24}$ For each of these areas, they provide examples for instructors on incorporating these ideas into the information literacy classroom. For example, in the area of teaching behaviors, they discuss how teacher enthusiasm, clarity in the delivery of course material, and positive interaction with students including using their names, offering praise, and deemphasizing power over students all contribute to increasing motivation.

Mortimore and Wall present the concepts of motivation and academic self-concept as they relate to African-American students, concluding that, through positive feedback, librarians can increase students' motivation and their academic self-concept. ${ }^{25}$ They offer several best practices that librarians can employ to create the perception of engagement, including collaborating with faculty on campus to present a "unified voice of authority and encouragement" to students, demonstrating effective teaching, 
developing assignments that include Kuhlthau's Information Search Process, and creating a culture of encouragement.

Pinto explored college students' self-assessed levels of motivation and self-efficacy beliefs on a set of 26 variables that measured IL skills. The results showed that generally the students reported higher motivation scores than self-efficacy scores, suggesting that their motivation to learn IL skills was greater than their belief in their ability to do so. ${ }^{26}$

\section{Coping}

Coping is defined as the thoughts and behaviors used to manage the internal and external demands of stressful situations. ${ }^{27}$ Research in coping examines how people respond to stress from real-life problems in terms of their behavior, emotion, and cognition. Given the variety of possible stressors, possible contexts, and possible coping responses humans enact, the number of coping strategies is nearly limitless. Thus, researchers have worked to develop a hierarchy of higher-order coping responses derived from the many observed and reported lower-order coping responses. An early theoretical attempt to understand coping described a two-function model: problemfocused coping, which included dealing with what caused the stressful situation, and emotion-focused coping, which sought to lessen negative emotions resulting from it. ${ }^{28}$ More recent empirically derived coping models include problem-focused and emotionfocused coping but also explore meaning-focused coping (using cognitive strategies to help make sense of a situation), social coping (seeking support from others), and avoidant coping (disengaging from or distracting oneself from the situation). ${ }^{29}$

Different forms of coping may influence students' acquisition of IL competencies. Coping theory suggests that problem-focused coping may be a more effective strategy toward managing stressful situations than emotion-focused or avoidant coping. The proactive, solution-oriented behaviors that follow problem-focused coping should encourage an objective approach to relieving stress. In contrast, emotion and avoidant coping, resulting in venting, mentally or behaviorally disengaging from the situation, or minimizing or seeking distraction from the stressful situation may hinder a person from moving beyond the situation. ${ }^{30}$ Coping by seeking support from others - either instrumental support or emotional support-could contribute to effective problemfocused coping when a student can accurately identify the person who can provide useful help or support. But seeking emotional support could also become less adaptive if used as an outlet to air negative feelings about the situation instead of trying to solve it. ${ }^{31}$

No specific research was found that examined the relationship between coping strategies and IL skills, but related findings from previous research show that the different coping strategies correlate with more general academic performance. MacCann, Fogarty, Zeidner, and Roberts found a positive correlation between problem-focused coping and students' GPA to be significant, and statistically significant negative correlations between emotion-focused and avoidant coping and GPA. ${ }^{32}$ Problem-focused coping was also statistically significantly correlated with undergraduate students' average grade at the end of an academic year (calculated by averaging all final course grades over the year)..$^{33}$

The theories discussed earlier make the case that information behavior and learning are processes that have important affective and cognitive elements. The development of IL skills, as an instantiation of both learning and information behavior, should thus be influenced by these same elements. Empirical research shows links between emotion and cognition and academic outcomes with some similar characteristics to IL skills acquisition, leading to the research reported here, which tests the relationship between emotion and cognition and IL skills. 


\section{Research Design}

Two studies explored how emotional and cognitive dimensions of students' development might be connected to their IL competency. The studies followed a quantitative research design using online surveys to collect cross-sectional data and statistical methods to analyze the data. The first study, carried out during a fall semester, was then replicated with data collected the following spring.

\section{Research Question and Hypotheses}

The research question guiding this study is: How do students' affect and cognition relate to their IL competencies? The following hypotheses outline the specific relationships and interactions among the variables.

1. Hypothesis 1: EI will be positively associated with IL.

2. Hypothesis 2: Dispositional affect will be associated with IL.

A. Positive affect will be positively associated with IL.

B. Negative affect will be negatively associated with IL.

3. Hypothesis 3: Motivation will be positively associated with IL.

4. Hypothesis 4: Coping will be associated with IL.

A. Active coping will be positively related to IL.

B. Seeking Support coping will be positively related to IL.

C. Avoidant coping will be negatively related to IL.

\section{Samples}

Both the fall and spring data sets were collected from undergraduate students enrolled in a lower-level basic communications course, COMM15000. Students voluntarily participated in the study and received course credit for their involvement. The survey was e-mailed to the participants, and they were given several weeks to complete the instrument. The final sample sizes were $\mathrm{N}=731$ for the fall group and $\mathrm{N}=375$ for the spring group.

\section{Instrument}

The instrument was developed with Qualtrics online survey software. Existing scales were used for each of the constructs measured. EI was measured with the Situation Test of Emotional Management (STEM). ${ }^{34}$ This 44 -item scale is an ability-based measure of the emotion management branch of EI. The instrument was created in Australia and a slightly modified version has been created, changing a few expressions to terms more common in U.S. English (for example, "workmate" to "coworker"). ${ }^{35}$ Each item briefly describes an emotional situation with five possible behavioral responses. Participants are instructed to choose the most effective course of action from among the five responses. A group of experts made up of professionally trained psychologists, life coaches with experience in counseling, and members in an EI research consortium were recruited to determine the best answers to each item. The 19 experts responded to each of the items and expert scores were determined in two ways: the average rating of the choice on a six-point scale, and the proportion of experts who selected that choice. Thus each item has a "best" response, based on the collective wisdom of the expert scorers. In all but three cases, both scoring methods resulted in the same option emerging as "best." In those three cases, I chose to use the response with the best average score between the two scoring methods as the correct response. Participant responses were scored against the correct answer. A sample question is, "Lee's coworker fails to deliver an important piece of information on time, causing Lee to fall behind schedule also. What action would be the most effective for Lee? A) Work harder to compensate; B) 
Get angry with the coworker; C) Explain the urgency of the situation to the coworker; D) Never rely on that coworker again.

Although many EI instruments exist, only a few treat EI as an ability, as conceptualized in this research. The STEM instrument is an ability-based measure of EI, is well tested psychometrically, and is freely available to researchers.

Dispositional affect was measured using the Scale of Positive and Negative Experience (SPANE). ${ }^{36}$ This 12 -item scale measures individual positive and negative affectivity. Six positive and six negative feeling terms are presented to participants who respond with an indication of how much they have experienced that feeling during the previous four weeks on a scale from 1 to 5 , where 1 is "very rarely or never" and 5 is "very often or always." Examples of the positive terms are pleasant, happy, and joyful. Negative terms include bad, sad, and angry. Calculating the responses produces a PA score from the positive terms and an NA score from the negative terms. This instrument was chosen because it includes both high and low arousal emotion terms where other instruments include only high arousal terms. Also, the SPANE instrument prompts respondents to think about the amount of time they have felt a given emotion term over a four-week period of time, which captures a range of emotions over time, rather than focusing on a single momentary mood captured by other instruments that frame the question in terms of how strongly a participant has felt an emotion.

Motivation was measured using the Conscientiousness scale from the IPIP 5-factor personality model. The personality trait conscientiousness, one of the factors in the Five Factor model of personality, has been used as a proxy for motivation in numerous studies because of its strong, consistent relationship with multiple theories of motivation. ${ }^{37}$ Individuals high in conscientiousness also exhibit high levels of motivation, across different conceptualizations and measurements of motivation. ${ }^{38}$ The scale contains 10 items - for instance: "I am always prepared" - and participants indicate the degree of accuracy of each statement on a five-point scale.

Coping was measured using the brief COPE inventory. ${ }^{39}$ The COPE instrument consists of 14 subscales of coping and measures coping strategies such as seeking a solution to the situation, using humor, trying to accept the situation, disengaging from the situation either mentally or behaviorally, venting emotions, blaming oneself, or seeking support. Respondents indicate on a four-point scale the frequency with which they employ the various coping strategies when under stress. A sample scale item is, "I take action to try to make the situation better." The strengths of this measure of coping are the range of subscales it uses that enable a more nuanced understanding of the variety of coping strategies, and that it balances situational influences with dispositional influences on how one copes.

IL scores were collected using the University of Arizona Information Literacy Test. ${ }^{40}$ Developed by librarians at the University of Arizona, this test includes 40 multiple-choice questions. Minor adaptations were made to questions that referred to specific resources or services at the University of Arizona so that they would fit the corresponding resources at Kent State University. Students' responses were scored against the correct answer. A sample question is, "You locate a great article for your topic on the effects of the recent drought on Australian wildlife. You want to find additional articles similar to this one. What would be the best course of action for you to take? A) Search the library catalog for other articles by the same author(s); B) Skim the bibliography for similar articles; C) Use the article's abstract to find similar articles; D) Use the library's "Citation Index" to find additional articles." The University of Arizona test was chosen because it was carefully constructed and tested using classical test theory and item response theory.

All the instruments used in this study were either freely available to researchers or permission was granted from the authors. 


\section{Limitations}

One limit to the study may be that the cross-sectional data captured at one moment in time may not fully reflect students' stable traits but rather their temporary conditions. Depending on when during the semester they completed the instrument, their emotions, motivation, and coping skills may have been more or less activated. Future research should consider a longitudinal approach, within a unit of time meaningful to the student population - a quarter, semester, or academic year. Another potential concern is how accurately information literacy can be measured using a standardized test. The IL instrument used in this study was chosen, among other reasons, because many of the items were written as situations or scenarios derived from real-world student experiences intended to capture students' abilities. Observing students enacting IL skills in real-life situations would perhaps more accurately measure IL ability.

\section{Findings}

Two preliminary analysis steps were performed prior to testing the hypotheses. I first analyzed the data sets according to the time respondents took in completing the instruments. I observed that a subset of respondents completed the instrument in a surprisingly short period of time (for instance, two minutes). Pilot testing of the instrument indicated that it should have reasonably taken approximately 45 minutes to complete the survey, so I categorized the data by time taken and isolated the fastest and slowest 10 percent. Then I compared the mean IL scores for the fastest, the slowest, and the middle group and found statistically significantly lower scores in the fastest 10 percent group, in both the fall and spring. I therefore elected to remove those responses from the data set, based on the assumption that the participants did not read the questions but just clicked through the instrument, which seemed to be supported in the analyses. Further analysis might suggest an even more conservative cutoff point.

To create the second-order constructs for the coping variable, I ran exploratory factor analysis (EFA) with promax rotation on both data sets to extract the latent factor structure from the data. EFA is a statistical process that reveals underlying factor structure in the data by identifying the items in an instrument that correlate strongly and those that correlate poorly to reveal the patterns in the data. In this case, EFA was used to examine the relationships among the 14 dimensions of the COPE scale to create second-order constructs of coping to carry out the hypothesis testing.

Several criteria were applied to determine the factor structure. The factors with eigenvalues of over 1 were examined and compared with a parallel analysis of the eigenvalues produced using Monte Carlo simulation method, which resulted in eight factors extracted for the fall data set and nine for the spring data set. ${ }^{41}$ An analysis of the scree plot for each data set, however, suggested a breaking point after three factors. The meaningfulness of the extracted factors relative to the theoretically derived coping models was also considered and resulted in using a three-factor model of coping for each data set.

As noted above, the coping instrument measures 14 coping strategies, doing so by asking two questions for each strategy. For the fall data set, the three factors and their specific coping items were:

1. Active and Positive Coping: both items from the active coping subscale (for instance, taking action to try to make the situation better), both items from the planning subscale (for example, thinking hard about what steps to take), and both items from the positive reframing subscale (such as trying to see the situation in a different light to make it seem more positive);

2. Seeking Support: both items from the subscales of seeking instrumental support (example: getting help and advice from other people) and emotional support 
(such as getting comfort and understanding from someone);

3. Avoidant Coping: both items from the self-blame subscale (like criticizing myself), and one item from the venting subscale (such as expressing my negative feelings).

The three-factor structure was also observed in the spring data set, but the set of items that loaded onto each factor changed slightly. Whereas fall respondents linked active coping with the concept of positively reframing the situation, in the spring data only the active and planning items were observed in the factor structure. Thus, the three-factor model from the spring data set was:

1. Active Coping: both items from the active coping and planning subscales;

2. Seeking Support: both items from the subscales of seeking instrumental and emotional support from others;

3. Avoidant Coping: both items from self-blame subscale, and one item from the venting subscale.

\section{Study 1}

Correlations among all variables were calculated to test for associations. Table 1 shows the means, standard deviations, and correlations for the study variables.

In table 1, the mean score for the EI instrument is 49.6 percent, while the mean score for the IL instrument is 42.3 percent. These two instruments were ability-based (as opposed to attitudinal or perceptionbased instruments) and indicate the degree to which the respondents are emotionally intelligent and information literate. The mean scores for these measures, at just below 50

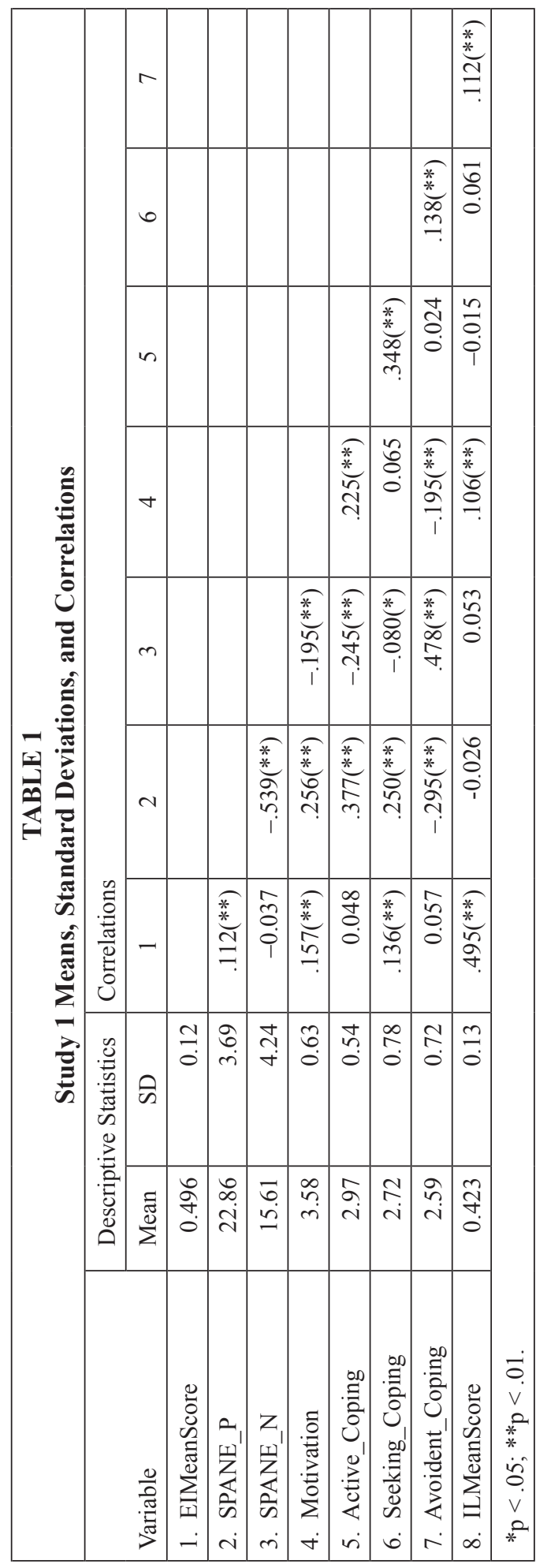


percent, show that, on average, students in this sample were only moderately skilled in these areas. Scores for positive and negative affect measured by SPANE can range from a low of 6 to a high of 30. The mean score for positive affect was 22.8, while the mean negative score was 15.6. On average, the dispositional affect scores tilt toward more positive feelings than negative feelings.

Several statistically significant correlations among the variables as hypothesized were observed. EI and IL were statistically significantly correlated $(r=0.495, p<0.01)$ and EI accounted for 24.5 percent of the variance in IL scores. Motivation and IL were also significantly correlated $(\mathrm{r}=0.106, p<0.01)$. An unexpected significant negative correlation was found between avoidant coping and IL $(r=0.112, p<0.01)$.

I also performed regression analysis to test the hypotheses. For the first hypothesis, students' IL scores were regressed on their EI scores. The unstandardized regression coefficient $(b=0.513)$ was also significant $(p<0.001)$, meaning that, for each point increase on students' EI scores, their IL score increased by .513. Thus hypothesis 1 was supported. Hypothesis 2 predicted an association between dispositional affect and IL, but an examination of the correlation data showed no significant relationships for positive or negative affect. Thus hypothesis 2 was not supported. Hypothesis 3 proposed that motivation would be positively associated with IL, and the correlation was statistically significant. Regression analysis also showed a positive relationship with a significant unstandardized coefficient $(b=0.021, p<0.01)$, supporting hypothesis 3 . Hypothesis 4 predicted that specific coping strategies would be associated with IL. However, contrary to the hypotheses, neither Active Coping nor Seeking Support Coping were associated with IL. Avoidant Coping was significantly positively related to IL, but with a very low correlation coefficient.

\section{Study 2}

Results of the same analysis carried out on the spring data set are in table 2 .

The average EI score for the spring group was 49.3 percent, and the average IL score was 41.6 percent-remarkably similar to the fall group. The mean scores for positive (22.96) and negative (15.5) affect were also similar to the averages for the fall group.

Statistically significant correlations were observed between EI and IL $(r=0.412, p$ $<0.01)$, between motivation and IL ( $r=0.227, p<0.01)$, and between Seeking Support coping and IL $(r=0.126, p<0.05)$. The unstandardized coefficient from the regression analysis of EI and IL was statistically significant $(b=0.410, p<0.001)$, supporting hypothesis 1 . As in study 1, there was no support for hypothesis 2-dispositional affect's relation to IL. Regression analysis of motivation and IL showed support for hypothesis 3 as predicted. The unstandardized coefficient for motivation $(b=0.004)$ was statistically significant $(p<0.001)$. Partial support for hypothesis 4 was observed. Of the three coping factors, Seeking Support coping was significantly correlated with IL $(b=0.021$, $p<0.05)$ as predicted, but the regression analysis was not significant.

\section{Discussion}

This study explored the relationship between representative constructs of students' emotions and cognition and their IL competency. The strongest relationship to IL was observed with the EI construct. In both studies, EI significantly predicted IL scores: The more emotional intelligence a student possessed, the higher her IL score. The other emotion variable, dispositional affect, did not relate significantly to IL scores. The hypotheses suggested that students with a more positive affective state should be better able to manage the emotional aspects of information behavior out of an ability to stay engaged, broaden and build on their actions, and thus better master IL competency; meanwhile, students with higher negative affect should experience the opposite effect. 


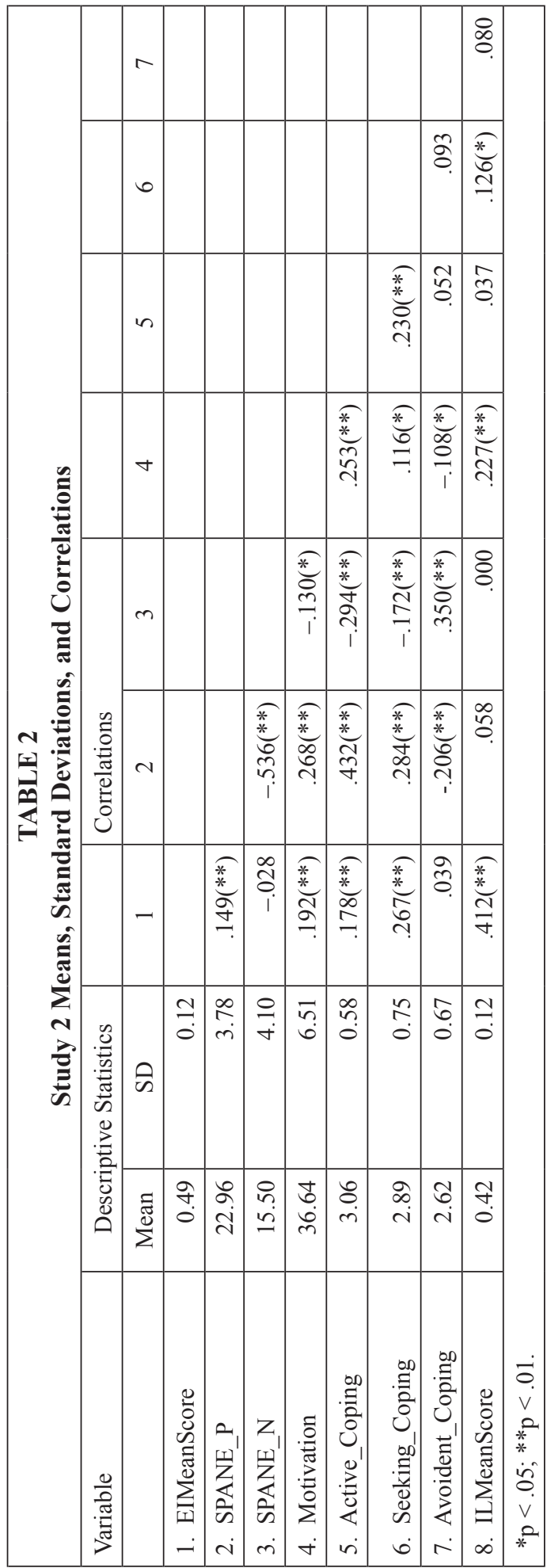

But, as the data showed, no such relationships were observed. It could be that any effect of dispositional affect on IL might be more visible during specific processes of acquiring IL skills, such as processes associated with seeking and using information, rather than when an outcome measure of IL knowledge is looked at, as was done in this research.

Of the two constructs representing students' cognitive dimension, motivation had a stronger relationship to students' IL scores than coping did. In both studies, motivation was significantly correlated with IL and a significant predictor of IL scores, although it explained a much smaller percentage of the variance in the IL scores than did EI. The three coping strategies did not show the predicted relationships with IL in the first study. In the second study, only the coping strategy of Seeking Emotional and Instrumental Support from others was associated as predicted with IL. The absence of a significant relationship here too may be attributable to the difference between measuring IL processes and IL knowledge.

Thus, of the two domains investigated, emotion, as measured by EI, has the strongest association with IL. This suggests that students who are better able to manage their emotions - who can identify a productive path through an emotionally taxing situation - may be better equipped to master IL skills. The IL skills commonly taught in academic settings expose students to the potential for affective experiences. Students with lower EI may find it more challenging to master the skills of IL if effectively managing their emotions is difficult for 
them. Previous theoretical and empirical research has demonstrated the presence of an affective dimension in peoples' information behaviors. ${ }^{42}$ Research has also shown positive associations between EI and academic success. ${ }^{43}$ The research reported here links these lines of research by demonstrating a significant relationship between EI and IL.

Motivation was also associated with IL. Students with greater levels of motivation had higher IL competency. This finding is consistent with literature that has linked the importance of motivation to IL. ${ }^{44}$ For example, Smith and Hepworth explored factors associated with school projects that detracted from students' motivation, concluding that students are demotivated by many of the phases of project work. They argue that more attention should be paid to IL instruction that recognizes "the motivational and emotional aspects of the project process." ${ }^{45}$ To that end, some research has explored factors that boost student motivation. Arnone, Reynolds, and Marshall found that eighth graders' intrinsic motivation was significantly associated with a number of contextual perceptions: 1) satisfaction of basic psychological needs, 2) the level of autonomy they felt in the school library, 3) perception of their librarians' understanding of computers, 4) their use of library resources, and 5) their searching online to satisfy a curiosity. In a university setting, Banas found that employing the technique of "behavioral construct tailoring" - using behavioral theory to inform the content of an instruction message to change or reinforce a desired behavior-contributed to an increase in students' perception of task attractiveness. ${ }^{46}$ The findings, coupled with these and other examples of research on integrating motivation with IL, make a strong case for strategically addressing student motivation in IL instruction.

\section{Implications for Practice}

The findings reported here suggest that it would be beneficial to adopt new models of IL instruction that integrate emotional and cognitive awareness with IL content. Some attention has been paid in the LIS literature to the discovery and incorporation of student affect into IL instruction. For example, Cahoy and Schroeder summarize best practices and provide guidance for how to write affective learning outcomes in IL and how to measure them. ${ }^{47}$ They surveyed IL librarians about their attention to their students' affective needs and found that a majority of their 275 respondents do address affective issues such as emotions toward research, attitude toward the library, and persistence in doing research in their IL sessions. ${ }^{48}$

Other models of instruction that integrate awareness of student affect can be found in the K-12 arena. Social and emotional learning (SEL) is an approach to teaching and learning in $\mathrm{K}-12$ education that emphasizes "strengthening a person's ability to understand, manage, and express the social and emotional aspects of life in ways that enable the successful accomplishment of life tasks, such as learning, forming relationships, solving everyday problems, and adapting to the complex demands of growth and development." ${ }^{\prime 9}$ Several curricula have been developed to introduce SEL concepts to elementary school-aged students, such as Strong Kids and The RULER Feeling Words Curriculum. ${ }^{50}$ Such programs focus on building students' social and emotional competencies by providing weekly instruction on five SEL skills: 1) self-awareness, 2) social awareness, 3) self-management, 4) social management, and 5) responsible decision making. ${ }^{51}$ Research comparing various personal and academic outcomes of students who have been exposed to SEL curricula with students who have not showed statistically significant higher scores on SEL knowledge, more perceived use of SEL skills, better teacher-rated social functioning, greater adaptability, higher grades in English and language arts, and improved work habits and social development ratings. ${ }^{52}$

Such a program may be a useful model to adapt to the university setting for IL instruction. The social and emotional concepts it addresses could be modified to match 
the developmental levels of college students and seamlessly integrated into IL instruction. Linking the social and emotional development of students with IL concepts is one way to focus on the whole student over a more narrowly structured instruction model focusing exclusively on discrete IL skills.

\section{Future Research}

This study served as an initial exploration into how students' emotional and cognitive characteristics relate to their IL competency. Much more research is needed to more fully explore these concepts. One line of research should continue exploration of the emotional dimension by testing the other branches of EI that were not included in this study. The Mayer-Salovey-Caruso Emotional Intelligence Test (MSCEIT) is the predominant instrument for measuring the four branches of ability-based EI, and follow-up research should consider using this instrument to capture students' EI ${ }^{53}$ Other research on an emotional track could explore the discrete emotions students feel as they are mastering IL skills. The Academic Emotions Questionnaire (AEQ) is an instrument developed to measure emotions specific to the academic environment. ${ }^{54}$ The AEQ measures eight emotions (enjoyment, hope, pride, relief, anger, anxiety, hopelessness, shame, and boredom) across three different academic environments (class-related, learning-related, and test-related); it could prove useful to researchers wishing to explore the effect of discrete emotions on IL.

Similar lines of inquiry should be considered for exploring students' cognitive dimension, perhaps using other measures for motivation and coping, as well as exploring other cognitive constructs such as need for achievement or goal orientation..$^{55}$ Instruments that distinguish among Deci and Ryan's intrinsic, extrinsic, and amotivation theoretical model of motivation, for example, could help further explain the role motivation plays in IL. ${ }^{56}$

Social influences should also be considered - for example, the effects on student IL skill development of their perceptions of peer, faculty, or librarian support. In essence, the "whole person" approach to understanding IL acquisition is an open field with many opportunities for new discovery and connection.

Finally, this research suggests some value for instruction librarians to partner with units on campus that focus on student life and development, such as the office of student affairs, or the office of residence life. These and similar units on campus provide support, training programs, and other experiences that contribute to students' learning. The links demonstrated in this study make a case for library collaboration with units like student affairs that offer cognitive and emotional development services to students.

\section{Conclusion}

IL continues to be a critically important issue to academic librarians. Over the years, much work has been done to establish best practices in content and delivery of IL instruction. A new line of IL research and practice should consider how students' cognitive, emotional, and social domains interact with or predict their ability to acquire IL skills. The research reported in this study shows a strong relationship between students' EI and IL, and a significant association between students' motivation and IL. Although exploratory, these findings suggest that librarians should enrich their IL instruction with techniques and strategies that consider the whole student-paying attention to their emotional and cognitive development-if they are to increase the effectiveness of the teaching and learning of IL skills. 


\section{Notes}

1. Jeffrey N. Gatten, "Student Psychosocial and Cognitive Development: Theory to Practice in Academic Libraries," Reference Services Review 32, no. 2 (2004): 160-61.

2. Carol C. Kuhlthau, "Inside the Search Process: Information Seeking from the User's Perspective," Journal of the American Society for Information Science 42, no. 5 (1991): 367.

3. Knud Illeris, The Three Dimensions of Learning: Contemporary Learning Theory in

the Tension Field between the Cognitive, the Emotional and the Social, trans. Dorothy Reader and Margaret Malone (Roskilde, Denmark: Roskilde University Press, 2002): 19-20.

4. Ibid., 227-28.

5. Peter Salovey and John D. Mayer, "Emotional Intelligence," Imagination, Cognition and Personality 9, no. 3 (1990): 189.

6. John D. Mayer et al., "Emotional Intelligence as a Standard Intelligence," Emotion 1, no. 3 (2001): 233.

7. Salovey and Mayer, "Emotional Intelligence," 185-211.

8. John D. Mayer and Peter Salovey, "What Is Emotional Intelligence?" in Emotional Development and Emotional Intelligence: Educational Implications, eds. Peter Salovey and David Sluyter (New York: BasicBooks, 1997), 3-31.

9. Ibid., 11.

10. Melissa Bowles-Terry, "Library Instruction and Academic Success: A Mixed-Methods Assessment of a Library Instruction Program," Evidence Based Library and Information Practice 7, no. 2 (2012), 82-95.

11. P. Qualter et al., "Ability Emotional Intelligence, Trait Emotional Intelligence, and Academic Success in British Secondary Schools: A 5year Longitudinal Study," Learning and Individual Differences 22, no. 1 (2012): 89.

12. Susan E. Rivers et al., "Measuring Emotional Intelligence in Early Adolescence with the MSCEIT-YV: Psychometric Properties and Relationship with Academic Performance and Psychosocial Functioning," Journal of Psychoeducational Assessment 30, no. 4 (Aug. 2012): 358.

13. Lynda Jiwen Song et al., "The Differential Effects of General Mental Ability and Emotional Intelligence on Academic Performance and Social Interactions," Intelligence 38, no. 1 (Jan. 2010): 141.

14. David Watson, Lee A. Clark, and Auke Tellegen, "Development and Validation of Brief Measures of Positive and Negative Affect: The PANAS Scales," Journal of Personality and Social Psychology 54, no. 6 (1988): 1063.

15. Barbara J. Fredrickson, "The Role of Positive Emotions in Positive Psychology," American Psychologist 56, no. 3 (2001): 218.

16. Watson, Clark, and Tellegen, "Development and Validation of Brief Measures of Positive and Negative Affect," 1063 .

17. Randy Larsen, "The Contributions of Positive and Negative Affect to Emotional WellBeing," Psychological Topics 18, no. 2 (2009): 251.

18 Ibid.

19. Fredrickson, "The Role of Positive Emotions in Positive Psychology," 219.

20 Ibid., 220.

21. Ashley D. Lewis et al., "The Incremental Validity of Positive Emotions in Predicting School Functioning," Journal of Psychoeducational Assessment 27, no. 5 (2009): 402.

22. Donald H. Saklofske et al., "Relationships of Personality, Affect, Emotional Intelligence and Coping with Student Stress and Academic Success: Different Patterns of Association for Stress and Success," Learning and Individual Differences 22 (2012): 256.

23. Richard M. Ryan and Edward L. Deci, "Intrinsic and Extrinsic Motivations: Classic Definitions and New Directions," Contemporary Educational Psychology 25, no. 1 (2000): 55.

24. Trudi E. Jacobson and Lijuan Xu, "Motivating Students in Credit-Based Information Literacy Courses: Theories and Practice," portal: Libraries \& the Academy 2, no. 3 (July 2002): 426.

25. Jeffrey M. Mortimore and Amanda Wall, "Motivating African-American Students through Information Literacy Instruction: Exploring the Link between Encouragement and Academic Self-Concept," Reference Librarian 50, no. 1 (Jan. 2009): 38-39.

26. M. Pinto, "An Approach to the Internal Facet of Information Literacy Using the IL-HUMASS Survey," Journal of Academic Librarianship 37, no. 2 (2011): 152.

27. Susan Folkman and Judith Tedlie Moskowitz, "Coping: Pitfalls and Promise," Annual Review of Psychology 55 (2004): 745.

28 Richard S. Lazarus and Susan Folkman, "Stress, Appraisal, and Coping," in (New York: Springer, 1984): 150-53.

29. Folkman and Moskowitz, "Coping: Pitfalls and Promise," 752.

30. Carolyn MacCann et al., "Coping Mediates the Relationship between Emotional Intelligence 
(EI) and Academic Achievement," Contemporary Educational Psychology 36 (2011): 60.

31. Charles S. Carver, Michael F. Scheier, and Jagdish Kumari Weintraub, "Assessing Coping Strategies: A Theoretically Based Approach," Journal of Personality and Social Psychology 56, no. 2 (1989): 269.

32. MacCann et al., "Coping Mediates the Relationship between Emotional Intelligence (EI) and Academic Achievement," 63.

33. Saklofske et al., "Relationships of Personality, Affect, Emotional Intelligence and Coping with Student Stress and Academic Success," 254.

34. Carolyn MacCann and Richard D. Roberts, "New Paradigms for Assessing Emotional Intelligence: Theory and Data," Emotion 8 (2008): 540-51.

35. James A. Scrivani, "Validating a Situational Based Emotional Intelligence Measure in an Organizational Context" (doctor dissertation, Alliant International University).

36. Ed Diener et al., "New Measures of Well-Being," in Well-being: The Collected Works of Ed Diener, ed. Ed Diener, vol. 39 (New York, N.Y.: Springer Science + Business Media, 2009), $247-66$.

37. Lewis R. Goldberg, "An Alternative 'Description of Personality'," Journal of Personality and Social Psychology 59, no. 6 (1990), 1216-29; Joseph C. Rode et al., "Emotional Intelligence and Individual Performance: Evidence of Direct and Moderated Effects," Journal of Organizational Behavior 28, no. 4 (2007): 403.

38. Timothy A. Judge and Remus Ilies, "Relationship of Personality to Performance Motivation," Journal of Applied Psychology 87, no. 4 (2002): 803.

39. Charles S. Carver, "You Want to Measure Coping but Your Protocol's Too Long: Consider the Brief COPE," International Journal of Behavioral Medicine 4, no. 1 (Jan. 1997): 92.

40. Yvonne Mery, Jill Newby, and Ke Peng, "Assessing the Reliability and Validity of Locally Developed Information Literacy Test Items," Reference Services Review 39, no. 1 (2011): 98-122.

41. Masaki Matsunaga, "How to Factor-Analyze Your Data Right: Do's, Dont's, and How-to's," International Journal of Psychological Research 3, no. 1 (Jan. 2010): 102-03.

42. Lesley S.J. Farmer, "Developmental Social-Emotional Behavior and Information Literacy," in Information and Emotion: The Emergent Affective Paradigm in Information Behavior Research and Theory, eds. Diane Nahl and Dania Bilal (Medford, N.J.: Information Today, 2007), 99-119; Ina Fourie, "Learning from Research on the Information Behaviour of Healthcare Professionals: A Review of the Literature 2004-2008 with a Focus on Emotion," Health Information E Libraries Journal 26, no. 3 (2009), 171-86; Lisa M. Given, "Emotional Entanglements on the University Campus: The Role of Affect in Undergraduates' Information Behaviors," in Information and Emotion: The Emergent Affective Paradigm in Information Behavior Research and Theory, eds. Diane Nahl and Dania Bilal (Medford, N.J.: Information Today, 2007), 161-241; Diane Nahl, "The Centrality of the Affective in Information Behavior," in Information and Emotion: The Emergent Affective Paradigm in Information Behavior Research and Theory, eds. Diane Nahl and Dania Bilal (Medford, N.J.: Information Today, 2007), 3-37.

43. Annamaria Di Fabio and Letizia Palazzeschi, "An In-depth Look at Scholastic Success: Fluid Intelligence, Personality Traits or Emotional Intelligence?" Personality and Individual Differences 46, no. 5/6 (2009): 581-85; James D.A. Parker et al., "Emotional Intelligence and Academic Success: Examining the Transition from High School to University," Personality and Individual Differences 36, no. 1 (2004), 163-72.

44. Andrew K. Shenton and Megan Fitzgibbons, "Making Information Literacy Relevant," Library Review 59, no. 3 (2010), 165-74.

45. Marian Smith and Mark Hepworth, "An Investigation of Factors That May Demotivate Secondary School Students Undertaking Project Work," Journal of Librarianship and Information Science 39, no. 1 (2007): 12.

46. Jennifer R. Banas, "Borrowing from Health Communications to Motivate Students to Learn Information Literacy Skills," Community \& Junior College Libraries 15, no. 2 (Apr. 2009): 77.

47. Ellysa Stern Cahoy and Robert Schroeder, "Embedding Affective Learning Outcomes in Library Instruction," Communications in Information Literacy 6, no. 1 (Mar. 2012), 73-90.

48 Ibid., 82.

49. Jeffrey S. Kress, Jacqueline A. Norris, and Dena A. Schoenholz, "Bringing Together Educational Standards and Social and Emotional Learning: Making the Case for Educators," American Journal of Education 111, no. 1 (Nov. 2004): 71.

50. K.W. Merrell et al., Strong Kids: A Social and Emotional Learning Curriculum for Students in Grades 3-5 (Baltimore: Brookes, 2007).

51. Collaborative for Academic, Social, and Emotional Learning, "What Is SEL?" available online at http://casel.org/why-it-matters/what-is-sel/ [accessed 16 May 2013].

52. Marc A. Brackett et al., "Enhancing Academic Performance and Social and Emotional Competence with the RULER Feeling Words Curriculum," Learning and Individual Differences 22, no. 2 (Apr. 2012): 22. 
53. John D. Mayer et al., "Measuring Emotional Intelligence with the MSCEITV2.0," Emotion 3, no. 1 (2003): 97-105.

54. Reinhard Pekrun et al., "Academic Emotions in Students' Self-Regulated Learning and Achievement: A Program of Qualitative and Quantitative Research," Educational Psychologist 37, no. 2 (2002): 91-105.

55. Carole Ames and Jennifer Archer, "Achievement Goals in the Classroom: Students' Learning Strategies and Motivation Processes," Journal of Educational Psychology 80, no. 3 (1988): 260-67.

56. Sarah R. Baker, "Intrinsic, Extrinsic, and Amotivational Orientations: Their Role in University Adjustment, Stress, Well-being, and Subsequent Academic Performance," Current Psychology 23, no. 3 (2004): 189-202; Ryan and Deci, "Intrinsic and Extrinsic Motivations," 54-67. 